\title{
A Study on Deformation Characteristics of Preloading Project in Permafrost Area
}

\author{
MA Xi-lei ${ }^{1, a}$, LIU Yan-xiang ${ }^{1, b}$,YI Jun-jian ${ }^{2}$ \\ ${ }^{1}$ Tianjin Research Institute for Water Transport Engineering, Tianjin, China \\ ${ }^{2}$ China Three Gorges University, Yichang, China \\ amaxilei1984@163.com, b371264354@qq.com
}

\begin{abstract}
Keywords: Permafrost area, Preloading, Deformation, Settlement, Monitoring
Abstract. This article is on the basis of an actual preloading project of permafrost region in Dalian, China. The deformation characteristics of preloading project in permafrost area can be found by the following steps: Initially, do some surveys about the geological characteristics of this project. Then, lay out the monitoring and detecting instrument, and record the construction process of foundation reinforcement. Eventually, analyze the data and reveal the change rules of the foundation settlement, pore water pressure, lateral displacement and underground water level elevation under the influence of temperature. If the deformation characteristics of preloading project in permafrost area are founded, it can provide a good reference for the similar projects and it is of important guiding significance for the similar projects in this region.
\end{abstract}

\section{Introduction}

Eastern coastal areas develop fast, the land resources have become more and more prominent, and it can hardly meet the requirements of the coastal cities in recent years, so the reclamation has become an important method to solve this problem. Among the reclamation, hydraulic fill has been widely used in many places. But there are still some problems existed in this method: first, it's difficult for the hydraulic fill to get fully consolidated in the initial years; second, the hydraulic fill that just finished is of high water content, high compressibility, high porosity ratio and low bearing capacity, which will bring adverse effect to the construction; third, Dalian is located in seasonal frozen soil regions, hydraulic fill has been hardly used in Dalian, what's more, there are not rich experiences in dealing with the filled foundation. So using the method of preloading belongs to a new attempt and it will present important references to the similar projects in this region.

Based on testing engineering of dealing with the soft foundation of Dalian Ocean University New Campus in China, this article adopts preloading to consolidate the foundation of testing area, and combines with the monitoring to know and master the dynamic deformation of the soft foundation during construction and preloading period, thus the soft foundation deformation and pore water pressure can be controlled effectively, and the safety and stability of soft foundation can also be ensured during construction. Besides, we can also explore the influences of freezing and thawing cycle of the soft foundation towards the consolidation settlement and stability of Dalian region hydraulic filled soft foundation.

\section{Project Profile}

This project that deals with the soft foundation at construction sites of Dalian ocean university new campus is located at the south bank of Bohai bay of Liaodong peninsula in China. The landforms of test sites are sea plain and mountain sloping fields, the test zone of project is a $60 \mathrm{~m} *$ $80 \mathrm{~m}$ rectangular space, and the total area is $4800 \mathrm{~m} 2$, and the schematic plan of test zone is shown in Fig.1. 


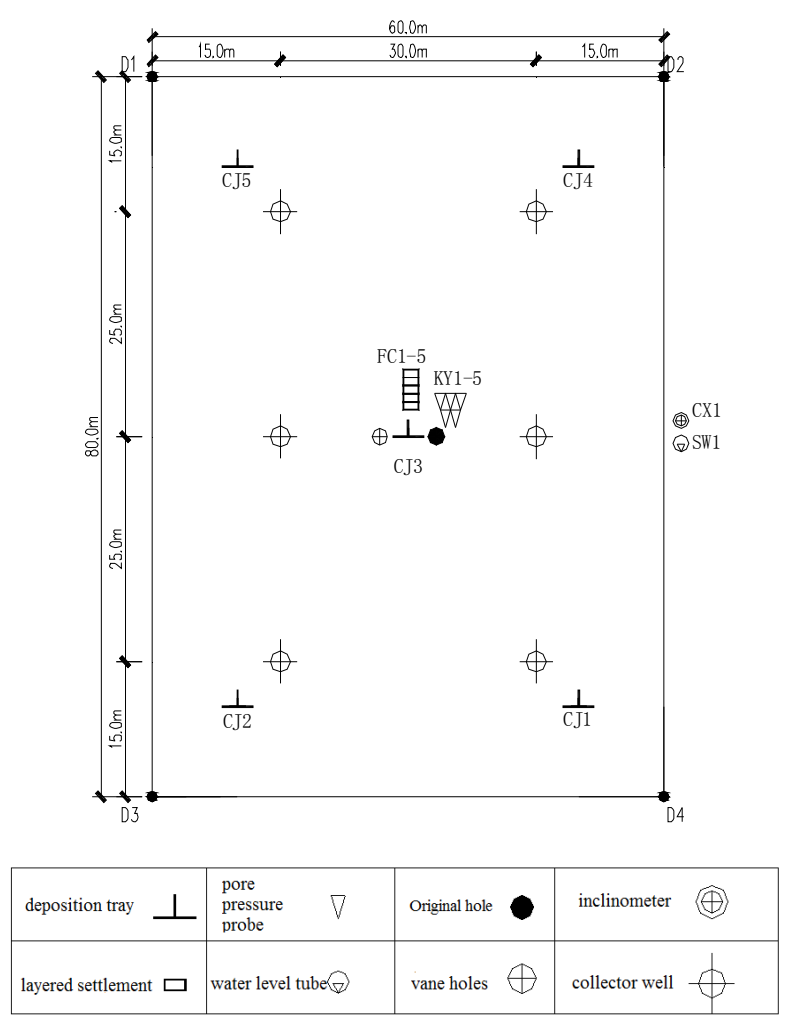

Fig.1. The sketch map of reinforced area and layout of measure points

According to the engineering geologic investigation data, the soil in this project is mostly made up of mud, muddy-silty clay and silty clay, the thickness of freshly hydraulic fill is about $3.0 \mathrm{~m}$, and the sediment concentration is high in the lower soli layer of dredger fill.

Surcharge preloading was adopted to consolidate the foundation of testing area in this project. The specific construction process is as follows: laying $0.5 \mathrm{~m}$ thick sand cushion on the soil surface of testing zone; setting plastic drains; the space of two plastic drains is $0.8 \mathrm{~m}$ and it should be arranged at square; loading hill-skill soil three times at testing zone, and the three loading heights are $1.0 \mathrm{~m}, 1.5 \mathrm{~m}$ and $2.0 \mathrm{~m}$ respectively, the total loading pressure is $89 \mathrm{kPa}$ (including $0.5 \mathrm{~m}$ thick sand cushion).

Monitoring of construction process mainly includes: surface settlement monitoring, layered settlement monitoring, pore water pressure monitoring and deep horizontal displacement monitoring, and there should be five surface settlement monitoring points, one layered settlement monitoring point, five pore water pressure monitoring points and one deep horizontal displacement monitoring point. Layout of monitoring instruments at testing zone has been shown in Fig.1.

\section{Analysis of Surface Settlement}

Five surface settlement monitoring points should be buried at the center and four corners of the rectangular testing area respectively, the specific burying positions are shown in Fig.1. Loading process lines and monitoring points surface settlement change process lines at testing zone have been given in Fig.2. 


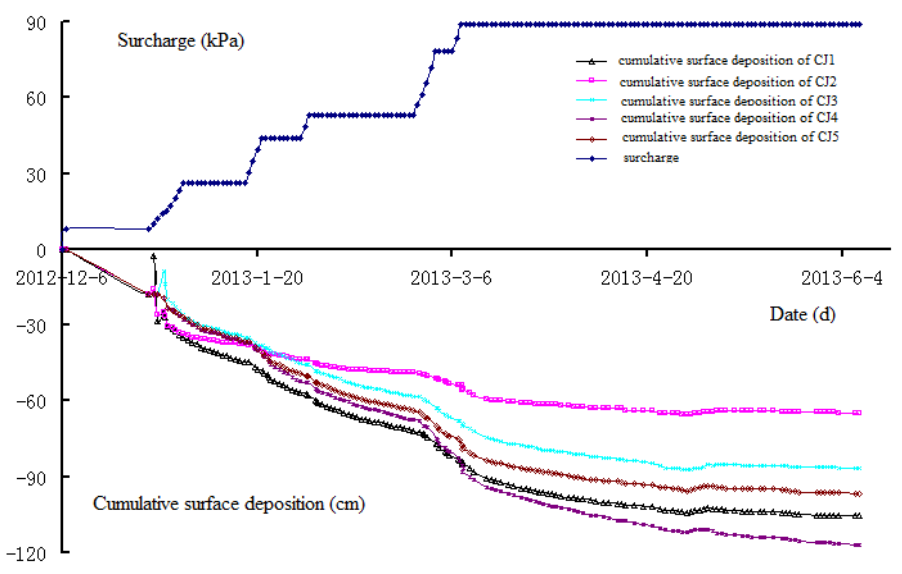

Fig.2 Loading curves of surcharge preloading area

There is a common characteristic in the change of surface settlement in each monitoring point, from 6 December 2012 to 6 January 2013,surface settlement of each monitoring point increased significantly; from 6 January 2013 to 15 January 2013, surface settlement of each monitoring point had significantly fluctuations; from 15 January 2013 to 1 March 2013,surface settlement of each monitoring point showed not significant changes; from 1 March 2013 to 15 March 2013, surface settlement of each monitoring point increased significantly; and from 15 March 2013 to 8 June 2013, surface settlement of each monitoring point showed not significant changes. The main reasons why surface settlement change process above occurred are as follows: from 6 December 2012 to 6 January 2013, setting plastic drains and loading the first batch of hill-skill soil make surface settlement of each monitoring point increase significantly. From 1 March 2013 to 15 March 2013, big changes of temperature resulted in the cycle of freezing and thawing of sand cushion and surface soil, and it led to fluctuations of surface settlement during this period. According to the meteorological data, it was the coldest period from 6 January 2013 to 11 January 2013 that year, and the actual frost depth of soil was $1.68 \mathrm{~m}$ during this period. The depth of the first batch of hill-skill soil is $1.0 \mathrm{~m}$, and the depth of sand cushion is $0.5 \mathrm{~m}$, so sand cushion and soil beneath the surface with the range of $0.18 \mathrm{~m}$ are all within the frost line. Sand cushion became frozen soil and failed to transverse drainage during this period, thus the water in the soil gathered on the surface and formed excess hydrostatic, reduced the surface settlement. Temperatures of Dalian area rose from 11 to 13 January, and maximum temperature was above zero, sand cushion became thawed and started to transverse drainage, combined with pumping, the water gathered in the surface of soil was drainaged fast, so surface settlement increased. The cycle of freezing and thawing of sand cushion and surface soil resulted in fluctuations of surface settlement during this period. From 1 March 2013 to 15 March 2013, the minimum temperature of Dalian area is above zero during this period, frozen soil layer started to melt gradually, foundation pressure of soft foundation became greater gradually, and that caused the obvious increase of settlement of each monitoring point on the surface of soft foundation.

In the process of foundation treatment (2012.12.26 2013.6.8), the amount of total settlements (including settlement during setting plastic drains) of each monitoring point (CJ1、CJ2、CJ3、CJ4、 CJ5) on the surface of foundation are $1054 \mathrm{~mm} 、 648 \mathrm{~mm} 、 867 \mathrm{~mm} 、 1171 \mathrm{~mm}$ and $965 \mathrm{~mm}$ respectively, the average total settlement is $941 \mathrm{~mm}$, the average subsidence velocity is $5.7 \mathrm{~mm} / \mathrm{d}$.

\section{Analysis of Layered Settlement}

The monitoring holes of layered settlement were damaged during construction at 28 December 2012, only the second stage and the third stage layered settlement were monitored during the loading, so the total layered settlements were relatively small. Fig.3 shows the layered settlement cumulative settlement process lines of layered settlement of monitoring point FC1-5 which was the newly set monitoring holes of layered settlement at 11 January 2013.According to Fig.3, the settlement of different depths was marvelous during initial loading period, as time goes by, the 
subsidence velocity decreased gradually, it turned out that the settlement of different depths was a process of gradual convergence. Because silt stratification in reinforced area is relatively thick has relatively single property, variation law of subsurface settlement of different depths is obvious: subsurface settlement on the surface is marvelous, among these, magnet ring 1 with $1.5 \mathrm{~m}$ buried depth has the largest settlement $(226 \mathrm{~mm})$; with the increase of soil depth, the settlement showed a tendency to decrease, among these, magnet ring 6 with $13 \mathrm{~m}$ buried depth has the least settlement $(52 \mathrm{~mm})$. According to the analysis of magnet ring settlement, the settlement of magnet ring 6 is obvious, it turned out that the effect influence depth of surcharge preloading can reach $13.0 \mathrm{~m}$ below the surface.

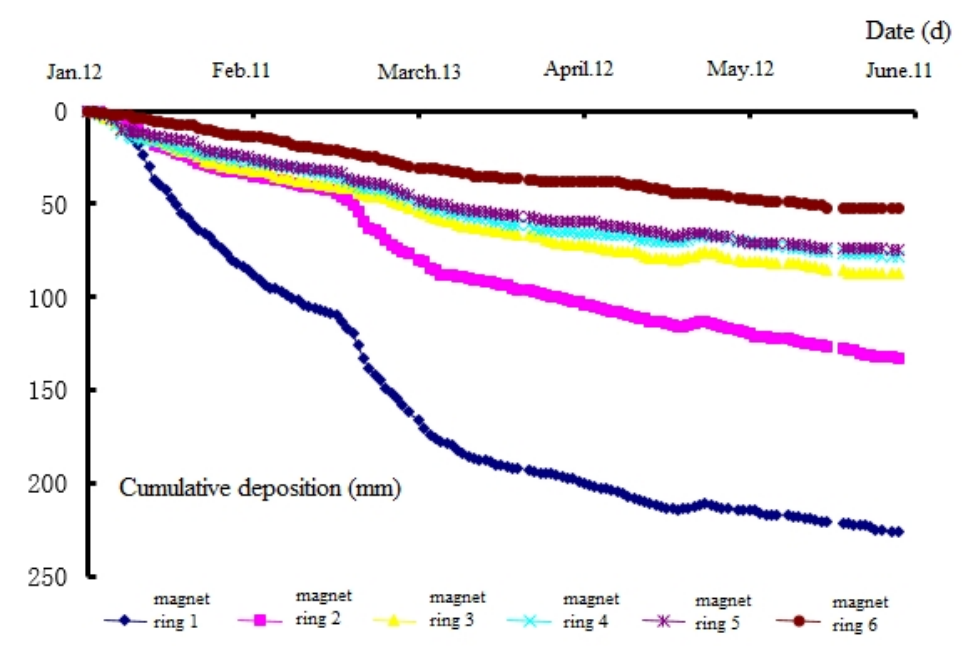

Fig.3 Change curves of layered settlement of FC1-5 at surcharge preloading area

According to the settlement variation law of magnet ring 1 6, the settlement variation law of silt stratification is consistent with that of surface, and the settlement variation law of soil below silt stratification is far from that of surface, as can be seen, the closer the soil to the surface, the closer to the surface of the soil, the settlement is significantly affected by the surface temperature.

\section{Analysis of Pore Water Pressure}

The pore water pressure is the most direct way to know consolidation state of soil, according to the variation law of pore water pressure, and after analyzing the consolidation mechanism of foundation soil, further studies on consolidation mechanism and increasing rules of soil strength can be carried on, and reinforcement effect of reinforced soil can also be judged. Process lines of pore water pressure of different depths over time have been shown in Fig.4. Fig.4 shows that there was a corresponding relationship between pore water pressure of each monitoring point and construction loading during loading period, pore water pressure increased obviously after each loading, and those increased relatively greatly were most in silt stratification. Pore water pressure reached a maximum when the loading was finished, after that it dissipated gradually in a steady state. Rate of dissipation was fast in the earlier stage, as time goes by, rate of dissipation decreased gradually and reached a plateau eventually. The pore water pressure curve undulated slightly in the rest of time was mainly because of the influences of construction near the testing area and season rainfall. Up to 5 June 2013, cumulative dissipation values of pore water pressure in different depths of soft foundation were varied, among all the monitoring points, the monitoring point with the $12 \mathrm{~m}$ depth has the maximum pore water pressure cumulative dissipation $(16.76 \mathrm{kPa})$, the monitoring point with the $6 \mathrm{~m}$ depth has the minimum pore water pressure cumulative dissipation $(8.72 \mathrm{kPa})$.

From 26 December 2012 to 15 January 2013, the cumulative dissipation of pore water pressure was much larger than increment of pore water pressure that caused by surcharge preloading, this indicated that during the foundation reinforcement, soil freezing also caused the different degrees of dissipation of pore water pressure except the dissipation caused by surcharge preloading. 


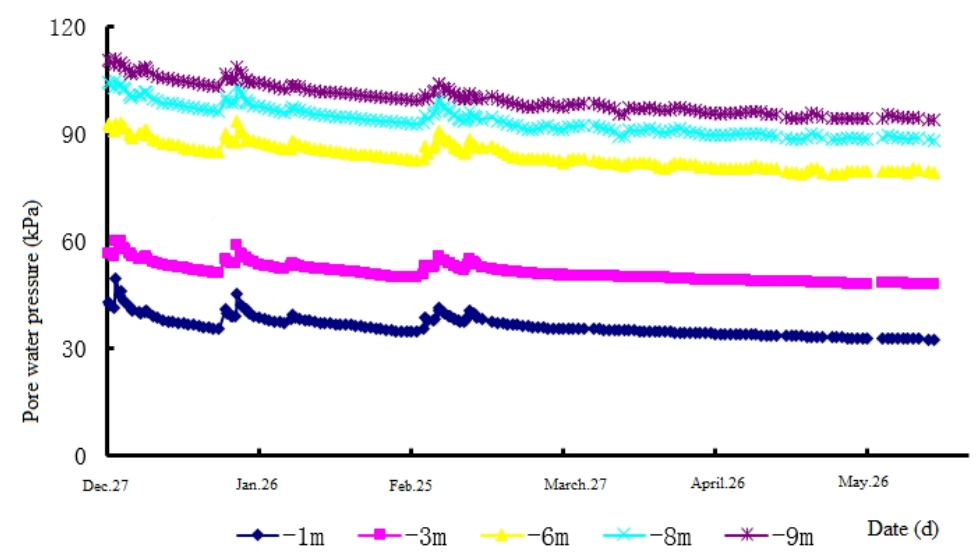

Fig.4 The change curves of pore water pressure at surcharge preloading area

\section{Analysis of Deep Displacement}

Soil in the reinforced area had a lateral horizontal displacement in the effect of surcharge preloading. The curves of soil lateral horizontal displacement changed with depth at testing area monitoring point CX1 is shown in Fig.5.According to Fig.5, general horizontal displacement moved from the inside to the outside, and the maximum cumulative lateral displacement $(445.60 \mathrm{~mm})$ of CX1(5 June 2013) was at a depth of $2.0 \mathrm{~m}$ below the surface. According to the distribution characteristic of curve, the general lateral displacements increased greatly during the loading, it indicated that the loading process influenced the increase of lateral displacement greatly. Lateral displacement of soft foundation within the range of $3.0 \mathrm{~m}$ below the surface is large, as the depth of soil increased, lateral horizontal displacement of soft foundation decreased rapidly, therefore, the increase of lateral displacement mainly occurred in silt stratification during the reinforcement process. Because the lateral displacement of surface is much larger than that of depth, and this led to the crack generation of testing area foundation surface during the reinforcement process, and the maximum crack width is $25 \mathrm{~cm}$.

The influences of temperature changes on lateral displacement of soft foundation are mainly from freezing to thawing of soft soil. Taking into the influences of filling during the freezing account, and the soft soil outside the inclinometer is of fast frozen speed and belongs to strong frost heave, so the soft foundation appeared reversed lateral displacement, and the maximum lateral displacement was about $4 \mathrm{~mm}$.

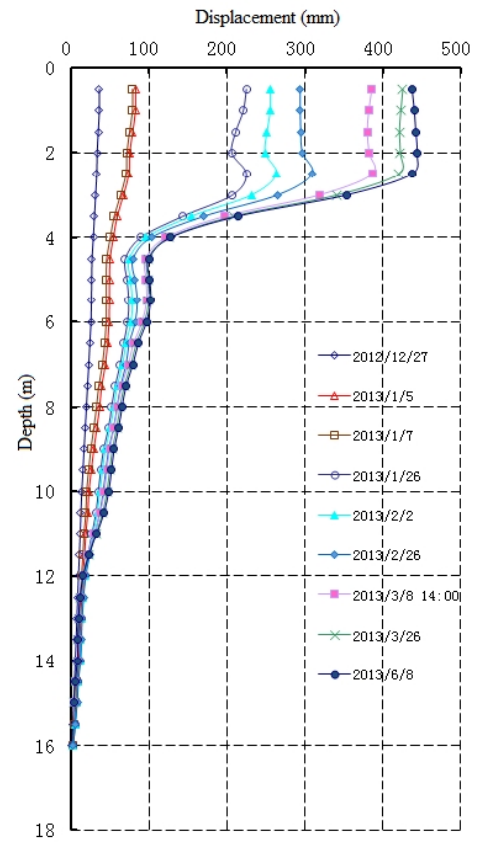

Fig.5 The change curves of deep lateral horizontal displacement of CX1 at testing area 


\section{Conclusions}

This article introduces the construction method and monitoring processes of reinforcing soft foundation in Dalian area with surcharge preloading in detail, and the conclusions are as followed:

(1) During the reinforcement of soft foundation, the closer the soil to the surface, the closer to the surface of the soil, the settlement is significantly affected by the surface temperature.

(2) There was a corresponding relationship between pore water pressure of each monitoring point and construction loading during loading period, pore water pressure increased obviously after each loading, and those increased relatively greatly were most in silt stratification.

(3) The lateral displacement and maximum displacement depth of soft foundation increase with the increase of loading, the increase of lateral displacement mainly occurred in silt stratification; during the freezing, the soft foundation appeared reversed lateral displacement.

\section{References}

[1] Technical Specification of Prototype Observation for Water Transport Engineering Hydrostructure, JTJ 218-2005.

[2] Tian Zhong. (2007) Construction Technique of Using Vacuum Preloading to Consolidate Soft-soil Foundation, Railway Engineering (in Chinese).

[3] ZHAO Hui, LI Liang-gang. (2005)The Consolidation Degree Of Using Load Pre-pressing Drainage Consolidation Method to Consolidate Soft-soil Foundation, Exploration Engineering, no. 3 (in Chinese).

[4] GUO Dian-ta, ZHENG Jian-hong. (2005)Design Method for Consolidation of Heap and Vacuum Preloading, Acta Agriculturae Universitatis Jiangxiensis, vol. 27, no. 4 (in Chinese).

[5] Zhen Xin-yang, Xu Feng, (2004)Application Comparison of Vacuum Preloading and Surcharge Preloading in Dealing With Super-soft Soil Foundation of Huanghua Port, Journal of Beijing Communications Management Institute for Executives, vol. 14, no. 1 (in Chinese).

[6] XU Guo-ping. (2009)Analysis of Vacuum Stow Combining Pre-pressing Method Reinforcing Shoal Soft Foundation, Foundation Engineering Testing and Monitoring, vol. 27, no. 8 (in Chinese). 